\title{
Evaluation of the antimicrobial activity of gooseberry and wild apple fruit juices of the northeast region of India
}

\author{
Kapil Punjabi', Vidushi Chitalia ${ }^{1 *}$, Tehmeena Mukadam¹, Jaishankar Sharma1, \\ Jinesh Maniar ${ }^{1}$, Shital Vasave ${ }^{1}$, Shashikant Vaidya ${ }^{1}$, L. Dikho Mao
}

${ }^{1}$ Department of Clinical Pathology, Haffkine Institute, Mumbai, India, ${ }^{2}$ Exotic Juices Pvt. Ltd. Manipur, India

\author{
Received: 27.01.2017 \\ Accepted: 01.03.2017 \\ *Address for \\ Correspondence: \\ Vidushi Chitalia, Department \\ of Clinical Pathology, \\ Haffkine Institute, \\ Acharya Donde Marg, \\ Parel - 400 012, Mumbai, \\ India. \\ Phone: 02224160947. \\ E-mail: vd.chitalia26@gmail. \\ com
}

\begin{abstract}
A large number of wild fruits belonging to the north eastern region of India are considered to be nutritionally abundant and traditionally used for the treatment of various ailments. In the present study, juices of gooseberry and wild apple have been evaluated for their antimicrobial activity in its consumable form as a potential source of natural anti-infective agent. The fruit juices were screened for their antibacterial and antifungal activities qualitatively, using the agar well diffusion method followed by quantitative assessment by determining the minimum inhibitory concentration and minimum bactericidal concentration. The study revealed that both the fruit juices exhibited broad spectrum antibacterial activity. Considerable activity against drug-resistant pathogens such as methicillin-resistant Staphylococcus aureus, vancomycin-resistant enterococci, and extended spectrum $\beta$-lactamases producing Gram-negative bacteria was observed. Thus, this study highlights the antibacterial efficacy of wild apple and gooseberry fruit juices and augments the beneficiary properties of highly nutritional fruit juices that are specific to Indian region.
\end{abstract}

KEY WORDS: Docynia indica, drug resistance, Emblica officinalis, polyphenols, tannins

\section{INTRODUCTION}

There has been a remarkable progress in the development of antibiotics.Yet, infectious diseases remain a major threat to public health worldwide. Moreover, there has been an alarming increase in antimicrobial resistance among the microbial pathogens causing various infections, thereby rendering numerous classes of antibiotics ineffective. There is, therefore, an increasing need to search for new antimicrobial agents (Bag et al., 2012). With growing interest in eco-living lifestyle, increased attention is being paid to the natural antimicrobial agents.

The foothill of eastern Himalayas offers a potential source of underutilized edible fruits. The region is explicitly rich in the mineral content which is apprehended in its native flora and fauna (Rymbai et al., 2016). A number of fruit juices have long been used and recommended for their use as an anti-infective agent in traditional medicine by the local tribes. These fruit juices have the properties of bioavailability and retention of certain minerals by bioactive polyphenolic compounds (Bansode and Chavan, 2013). Not only are these fruit juices cost-effective but also with disassociated side effects, which make them better alternatives for the currently available antibiotics (Bag et al., 2012; Bansode and Chavan, 2013).

Indian gooseberry (Emblica officinalis) commonly referred as "Amla" fruit has been traditionally associated with numerous health benefits. It is described as light green, round to transversely spherical fruit with astringent taste (Rudrappa, 2009). Indian gooseberry has been reputed to contain the highest proportion of vitamin $\mathrm{C}$ and antioxidants (Shishoo et al., 1997). Other health benefits reportedly include diuretic activity, anti-diabetic, detoxifying effects, strengthening of body organs, and strengthening of immune cells among others (Facts, 2016).

Another fruit used in traditional medicine is the wild apple located in parts of eastern Asia. Wild apples (Docynia indica) vary from their domesticated counterparts in being one-third their size and are bitter to sour in taste 
(Rymbai et al., 2016). It is known as crab apple in English and locally as "Sohphoh Khasi." It is popular and regarded as the "health fruit" among the tribes of Meghalaya and Nagaland. The medicinal benefits accredited include stimulation of appetite, improved digestion, reduction in bloating, treatment of heartburn, controlling high blood pressure, and anti-diabetic activities (NagalandPost, 2012; Rymbai et al., 2016).

These fruit juices with their nutritional benefits are known to exhibit antimicrobial activity. This feature roots for an important strategy in the establishment of alternative therapies to treat infection or avoid critical side effects associated with antibiotic therapies as these juices are completely natural in the source. Therefore, the present study was undertaken to evaluate the antimicrobial activity of the fruit juices of gooseberry and wild apple grown in northeast India.

\section{MATERIALS AND METHODS}

\section{Fruit Juices}

The gooseberry and wild apple fruit juices were obtained from Exotic Juices Pvt. Ltd., Manipur, India.

\section{Test Cultures}

Pure cultures of Gram-negative organisms: Escherichia coli ATCC 25922, Klebsiella pneumoniae ATCC 10031, Enterobacter aerogenes ATCC 13048, Proteus mirabilis ATCC 21100, Salmonella abony ATCC 6017, Shigella boydii ATCC 8700, Pseudomonas aeruginosa ATCC 27853, and $K$. pneumoniae ATCC 700603(Extended Spectrum $\beta$-Lactamases, ESBL); Gram-positive organisms: Staphylococcus aureus ATCC 25923, S. aureus ATCC 6538, Staphylococcus epidermidis ATCC 12228, Bacillus subtilis ATCC 6633, S. aureus ATCC 43300 (methicillinresistant S. aureus, MRSA), and Enterococcus faecalis ATCC 51299 (vancomycin-resistant enterococci, VRE); fungal organisms: Candida albicans ATCC 10231 and Aspergillus brasiliensis ATCC 16404 were included in the study. The sources of these cultures were NCCS, Pune, India and HiMedia Labs Pvt. Ltd, Mumbai, India.

\section{Screening for Antimicrobial Activity}

The fruit juices were screened for its antibacterial and antifungal activities using agar well diffusion method (Hindi and Chabuck, 2013; Momand et al., 2014). The antibacterial activity was assayed using Mueller-Hinton $(\mathrm{MH})$ agar while Sabouraud dextrose agar was used for assessment of antifungal activity. Molten media containing $100 \mu \mathrm{L}$ of test inoculum $\left(1.5 \times 10^{8} \mathrm{cfu} / \mathrm{mL}\right)$ were poured into sterile Petri dishes and allowed to solidify. Wells of $6 \mathrm{~mm}$ diameter were bored and test samples were subsequently added to each well. The test samples included unfiltered fruit juice (UFJ) and particles of fruit juice. Furthermore, standard antimicrobials, amikacin $(30 \mu \mathrm{g} / \mathrm{mL})$ for antibacterial activity, and ketoconazole $(60 \mu \mathrm{g} / \mathrm{mL})$ for antifungal activity were included and sterile distilled water was used as the negative control for both. The plates were refrigerated for $1 \mathrm{~h}$ to diffuse the samples and incubated at $37^{\circ} \mathrm{C}$ for $24 \mathrm{~h}$ for antibacterial and at room temperature for $48 \mathrm{~h}$ for antifungal activities. The inhibition zone diameter of the test samples was measured and compared with the corresponding standard drugs to determine its efficacy. The \% activity was calculated with the below formula:

Formula (Rojas et al., 2006):

$$
\begin{aligned}
& \text { Zone diameter of test sample- } \\
& \% \text { Activity }=\frac{\text { Zone diameter of negative control }}{\text { Zone diameter of standard }} \times 100
\end{aligned}
$$

\section{Minimum Inhibitory Concentration (MIC) and Minimum Bactericidal Concentration (MBC)}

The MIC and MBC of the fruit juices showing antimicrobial activity were determined using broth dilution method (Pandey et al., 2011; Hindi and Chabuck, 2013). The confirmation of both MIC and MBC of the fruit juice/s against all test bacteria was determined by growth on solid media (Jayana et al., 2010; Pandey et al., 2011).

Dilutions of the test samples using double strength $\mathrm{MH}$ broth in the case of UJF and single strength MH broth for particles were prepared in required concentration. The UFJ was analyzed at $100 \%, 75 \%, 50 \%$, and $25 \%$; while the particles were used at $800 \mathrm{mg} / \mathrm{mL}, 600 \mathrm{mg} / \mathrm{mL}$, $400 \mathrm{mg} / \mathrm{mL}, 200 \mathrm{mg} / \mathrm{mL}, 100 \mathrm{mg} / \mathrm{mL}$, and $50 \mathrm{mg} / \mathrm{mL}$ concentrations. An inoculum of $100 \mu \mathrm{L}$ of test organism $\left(1.5 \times 10^{8} \mathrm{cfu} / \mathrm{mL}\right)$ was added to each concentration and incubated at $37^{\circ} \mathrm{C}$ for $24 \mathrm{~h}$. Post incubation, all the samples were plated onto $\mathrm{MH}$ agar plates.

\section{RESULTS AND DISCUSSION}

In the wake of increasing drug resistance toward existing antimicrobials, evaluation of alternate natural antimicrobial agents is the need of the hour. With their highly documented uses in ancient medicine, gooseberry and wild apple were easy choices. In the present study, the commercially available gooseberry and wild apple fruit 
juices from Exotic juices Pvt. Ltd. were tested for their antimicrobial properties.

The acquired fruit juices were slightly acidic in nature. The clear supernatant (unfiltered) juice and pulp (particles) were individually assessed for their antimicrobial activity.

\section{Screening Using Agar Well Diffusion Method}

The fruit juices were initially screened using agar well diffusion method for their antibacterial and antifungal activity (Figures 1 and 2). Amikacin and ketoconazole were used as standards for antibacterial and antifungal activities, respectively. Amikacin, an aminoglycoside is a potent broad-spectrum bactericidal agent effective against a wide range of infections (Gonzalez and Spencer, 1998). Ketoconazole is a derivative of imidazole and has been documented to be active against Candida and Aspergillus (Robinson et al., 2011; Spampinato and Leonardi, 2013).

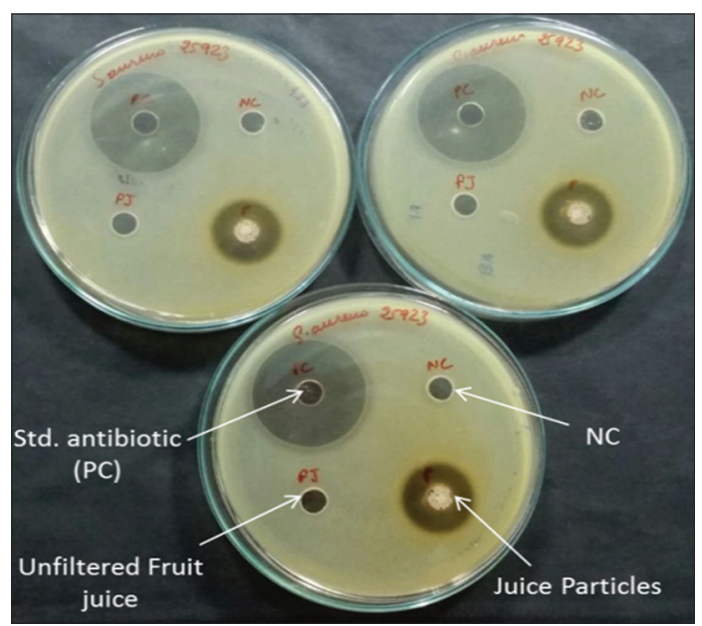

Figure 1: Screening of antimicrobial activity of gooseberry fruit juice (Legend: PC-positive control and NC-negative control)

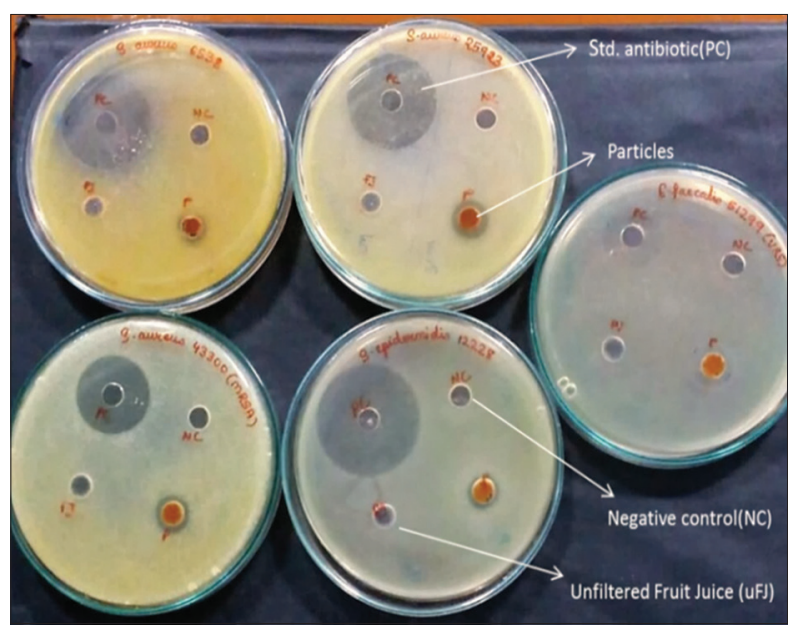

Figure 2: Screening of wild apple juice and particles against Grampositive organisms
The zone diameter of Amikacin observed against the test bacteria were within the range specified by CLSI (CLSI, 2014). The activities of test samples (unfiltered fruit juice and particles) were determined in percentage by comparing its activity with amikacin for bacterial cultures and ketoconazole for fungal cultures.

A broad-spectrum antibacterial activity was exhibited by both the juices. The activity of UFJ was observed against selected organisms while particles exhibited activity against all test organisms (Figures 3 and 4). In the case of wild apple, no activity was exhibited by the unfiltered juice while the particles showed activity against all the test bacteria (Figures 5 and 6).

Anti-fungal activity was not observed against the two test organisms for yeast and mold namely C. albicans ATCC 10231 and A.brasiliensis ATCC 16404. However, there were other studies that report activity of gooseberry against C. albicans (Ahmad and Beg, 2001). Similarly, the activity of gooseberry against Aspergillus had been described by some studies and contradicted by others (Hasan et al., 2016). The plant source, part of the plant used, a method of extraction and solvent of extraction plays an important part in case of activities (Zlotek et al., 2015). The anti-candida activity

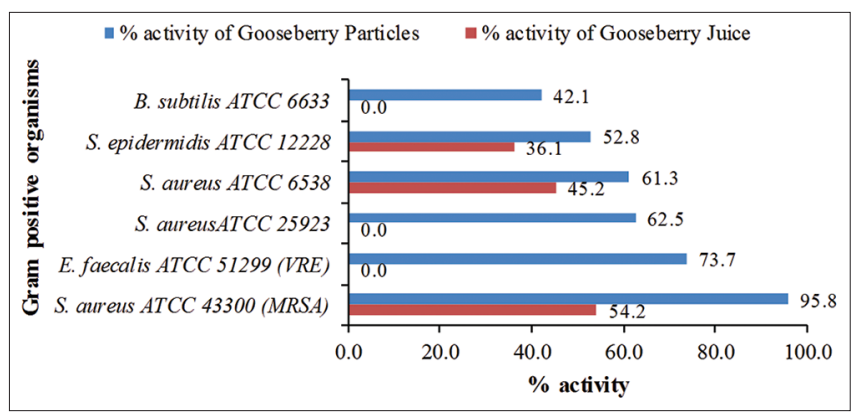

Figure 3: Activity of gooseberry fruit juice and particles against Grampositive organisms

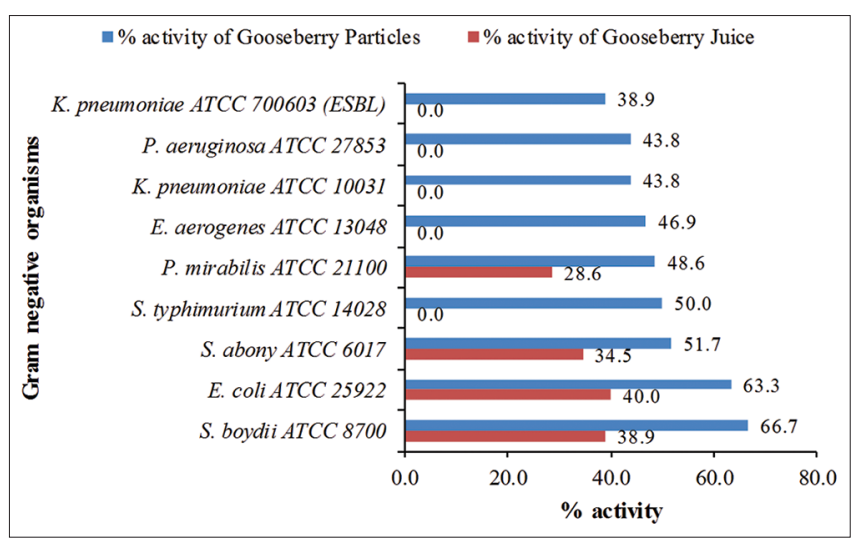

Figure 4: Activity of gooseberry juice and particles against Gramnegative organisms 
may be therefore associated with a different source or extract.

\section{MIC and MBC}

The MIC and MBC were determined for both the UFJ and its particles. The juices in its neat concentration did not support the sustenance of any organisms. This may be attributed to the acidic nature of the juices. The MIC of the wild apple particles ranged from 50 to $400 \mathrm{mg}$ for Gram-positive organisms and 50-800 mg for Gramnegative organisms. The MIC of the fruit juices has been tabulated in Tables 1-3. The MIC and MBC were confirmed by inhibition of growth on media plates (Figure 7).

In the present study, the fruit juice and particles of both gooseberry and wild apple showed strong activity against most of the tested bacteria. The results were compared with standard antibiotic drugs. Numerous mechanisms of antimicrobial activity of the fruits juices have been described. Although the exact target and mechanisms of the antimicrobial actions are not completely elucidated, the antimicrobial activity is mainly associated with the polyphenols and organic acids (Negi, 2012). Furthermore, in the case of natural products, identification of the specific site of action is difficult as various interacting reactions occur simultaneously (Davidson, 2001).

In the present study, gooseberry exhibited a higher antibacterial activity as compared to wild apple. Gooseberry fruits reportedly have a high fraction of hydrolysable tannins such as emblicanin A and B, punigluconin, and pedunculagin among others (Sawant et al., 2012; Dasaroju and Gottumukkala, 2014). Studies have previously reported the presence of alkaloids such as phyllemblin; flavonoids such as kaempferol and phenolic compounds including ellagic acid and gallic acid (Dharmananda, 2003; Habib-ur-Rehman et al., 2007). The phytochemicals of wild apple have also been studied earlier and it is reported to contain high amounts of phenolic compounds, mainly, gallic acid and rutin-like flavonoids (Shende et al., 2016). The variation in the polyphenol and organic acid content has been attributed to seasonal and regional variations. The gooseberry and wild apple juices in this study are from a highly conserved region the north east region of India.

The antimicrobial activity of gooseberry and wild apple may be accredited to their phenolic compounds and flavonoids (Cowan, 1999). Phenols influence the protein to lipid ratio, membrane functioning, and ion channels while the catechins are known to disrupt the

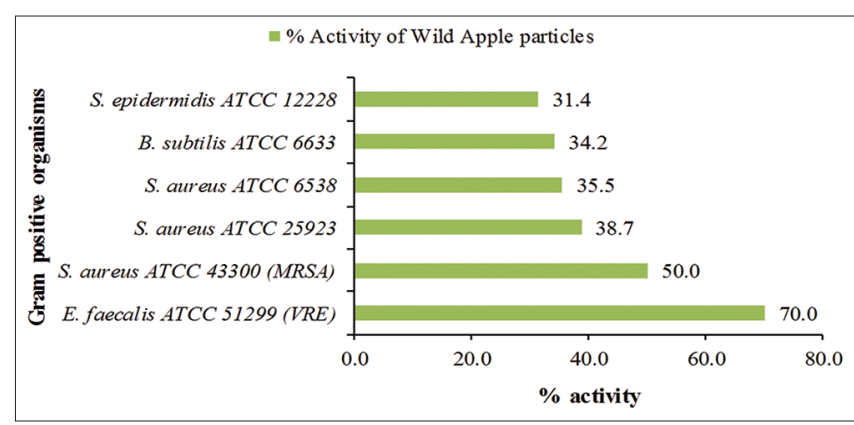

Figure 5: Activity of wild apple particles against Gram-positive organisms

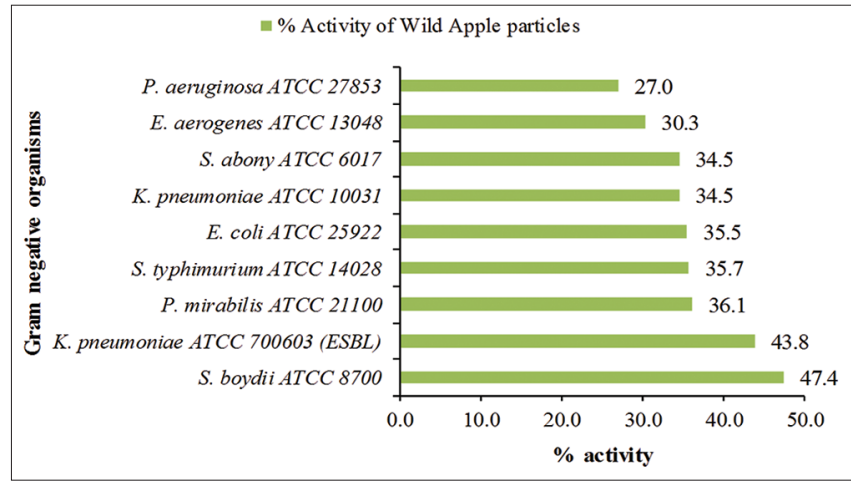

Figure 6: Activity of wild apple particles against Gram-negative organisms

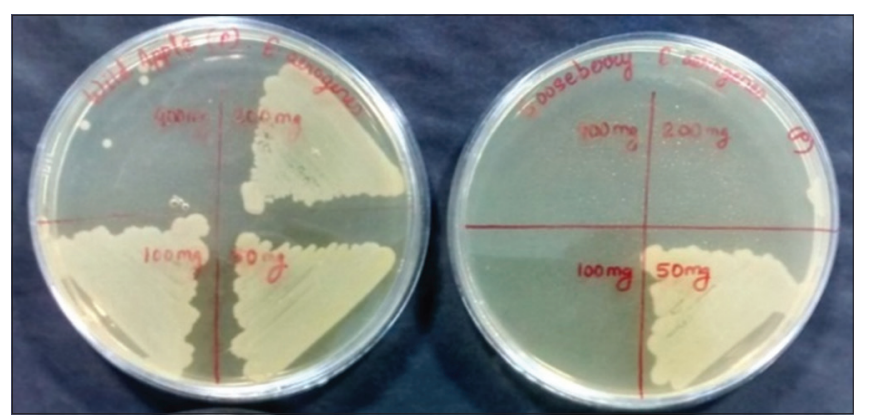

Figure 7: Minimum bactericidal concentration of particles

membrane integrity of the lipid bilayers. The flavonoid rutin present in wild apple has been reported to inhibit topoisomerase type II (Cushnie and Lamb, 2005). Kaempferolis known to have a high antibacterial activity against multidrug-resistant organisms such as MRSA and VRE (Xu and Lee, 2001). The antibacterial activity of kaempferol has been associated with the inhibition of protein kinase C (Shohaib et al., 2011). Fur thermore, alkaloids are thought to affect the genetic material in microorganisms thereby contributing to their antimicrobial activity (Negi, 2012).

The activity of both juices was observed against Gramnegative and Gram-positive organisms, with no particular 
Table 1: MIC and MBC of gooseberry and wild apple fruit juices (unfiltered juices)

\begin{tabular}{|c|c|c|c|c|c|c|c|c|c|c|c|}
\hline \multirow[t]{2}{*}{ Test organism } & & \multicolumn{5}{|c|}{ Gooseberry fruit juice } & \multicolumn{5}{|c|}{ Wild apple fruit juice } \\
\hline & & $100 \%$ & $75 \%$ & $50 \%$ & $25 \%$ & MIC/MBC (\%) & $100 \%$ & $75 \%$ & $50 \%$ & $25 \%$ & MIC/MBC (\%) \\
\hline \multirow{6}{*}{ Gram-positive } & S. aureus ATCC 25923 & - & - & - & - & $<25$ & - & - & - & + & $>25-50$ \\
\hline & S. aureus ATCC 6538 & - & - & - & - & $<25$ & - & - & - & - & $<25$ \\
\hline & S. aureus ATCC 43300 & - & - & - & + & $>25-50$ & - & - & + & + & $>50-75$ \\
\hline & S. epidermidis ATCC 12228 & - & - & - & - & $<25$ & - & - & - & + & $>25-50$ \\
\hline & E. faecalis ATCC 51299 & - & - & - & + & $>25-50$ & - & - & + & + & $>50-75$ \\
\hline & B. subtilis ATCC 6633 & - & - & - & - & $<25$ & - & - & - & - & $<25$ \\
\hline \multirow{9}{*}{ Gram-negative } & E. coli ATCC 25922 & - & - & - & - & $<25$ & - & - & ++ & +++ & $>50-75$ \\
\hline & K. pneumoniae ATCC 10031 & - & - & - & - & $<25$ & - & - & ++ & +++ & $>50-75$ \\
\hline & K. pneumoniae ATCC 700603 & - & - & - & - & $<25$ & - & - & + & +++ & $>50-75$ \\
\hline & E. aerogenes ATCC 13048 & - & ++ & ++ & ++ & $>75$ & - & - & - & +++ & $>25-50$ \\
\hline & S. typhimurium ATCC 14028 & - & - & - & ++ & $>25-50$ & - & - & ++ & +++ & $>50-75$ \\
\hline & S. abony ATCC 6017 & - & - & - & ++ & $>25-50$ & - & + & ++ & +++ & $>75$ \\
\hline & P. mirabilis ATCC 21100 & - & - & - & - & $<25$ & - & - & - & - & $<25$ \\
\hline & S. boydii ATCC 8700 & - & - & - & - & $<25$ & - & - & - & ++ & $>25-50$ \\
\hline & P. aeruginosa ATCC 27853 & - & - & - & ++ & $>25-50$ & - & - & - & +++ & $>25-50$ \\
\hline
\end{tabular}

+++ : Luxuriant growth, ++: Growth, +: Few colonies, -: No growth, MIC: Minimum inhibitory concentration, MBC: Minimum bactericidal concentration

Table 2: MIC and MBC of wild apple and gooseberry fruit juice particles against Gram-positive organisms

\begin{tabular}{|c|c|c|c|c|c|c|c|c|}
\hline \multirow[t]{2}{*}{ Test organism } & \multicolumn{4}{|c|}{$\begin{array}{c}\text { Gooseberry } \\
\text { particles }(\mathrm{mg} / \mathrm{mL})\end{array}$} & \multicolumn{4}{|c|}{$\begin{array}{c}\text { Wild apple } \\
\text { particles }(\mathrm{mg} / \mathrm{mL})\end{array}$} \\
\hline & 400 & 200 & 100 & 50 & 400 & 200 & 100 & 50 \\
\hline S. aureus ATCC 25923 & - & - & + & ++ & - & + & + & ++ \\
\hline S. aureus ATCC 6538 & - & - & - & - & - & + & + & ++ \\
\hline S. aureus ATCC 43300 & - & - & + & ++ & - & ++ & ++ & ++ \\
\hline S. epidermidis ATCC 12228 & - & - & - & ++ & - & - & ++ & +++ \\
\hline E. faecalis ATCC 51299 & - & + & ++ & ++ & - & + & ++ & ++ \\
\hline B. subtilis ATCC 6633 & - & - & - & - & - & - & - & - \\
\hline
\end{tabular}

+++ : Luxuriant growth, ++ : Growth, + : Few colonies, $-:$ No growth, MIC: Minimum inhibitory concentration, MBC: Minimum bactericidal concentration

Table 3: MIC and MBC of wild apple and gooseberry fruit juice particles against Gram-negative organisms

\begin{tabular}{|c|c|c|c|c|c|c|c|c|c|}
\hline \multirow[t]{2}{*}{ Test organism } & \multicolumn{4}{|c|}{$\begin{array}{c}\text { Gooseberry } \\
\text { particles }(\mathrm{mg} / \mathrm{mL})\end{array}$} & \multicolumn{5}{|c|}{ Wild apple particles $(\mathrm{mg} / \mathrm{mL})$} \\
\hline & 400 & 200 & 100 & 50 & 800 & 600 & 400 & 200 & 100 \\
\hline $\begin{array}{l}\text { E. coli } \\
\text { ATCC } 25922\end{array}$ & - & - & - & ++ & - & ++ & +++ & +++ & +++ \\
\hline $\begin{array}{l}\text { K. pneumoniae } \\
\text { ATCC } 10031\end{array}$ & - & - & - & ++ & - & - & +++ & +++ & +++ \\
\hline $\begin{array}{l}\text { K. pneumoniae } \\
\text { ATCC } 700603\end{array}$ & - & - & ++ & ++ & - & - & +++ & +++ & +++ \\
\hline $\begin{array}{l}\text { E. aerogenes } \\
\text { ATCC } 13048\end{array}$ & - & - & - & +++ & + & ++ & +++ & +++ & +++ \\
\hline $\begin{array}{l}\text { S. typhimurium } \\
\text { ATCC } 14028\end{array}$ & - & - & + & +++ & - & ++ & ++ & +++ & +++ \\
\hline $\begin{array}{l}\text { S. abony } \\
\text { ATCC } 6017\end{array}$ & - & - & - & ++ & - & - & ++ & +++ & +++ \\
\hline $\begin{array}{l}\text { P. mirabilis } \\
\text { ATCC } 21100\end{array}$ & - & - & + & ++ & - & - & - & - & ++ \\
\hline $\begin{array}{l}\text { S. boydii } \\
\text { ATCC } 8700\end{array}$ & - & - & - & + & - & - & & ++ & +++ \\
\hline $\begin{array}{l}\text { P. aeruginosa } \\
\text { ATCC } 27853\end{array}$ & - & - & - & + & - & - & ++ & +++ & +++ \\
\hline
\end{tabular}

+++ : Luxuriant growth, ++: Growth, +:Few colonies, -: No growth, MIC: Minimum inhibitory concentration, MBC: Minimum bactericidal concentration pattern. Previous studies have also reported a broadspectrum antibacterial activity in gooseberry and wild apple fruit extracts (Ahmad and Beg 2001, Shende et al., 2016). However, some remarkable results indicated that the juices and its particles had higher activity against the drug-resistant variants of bacteria such as MRSA, VRE, and ESBLs. This may be explained by the fact that the acquisition of drug resistance does not increase the innate virulence of the organism due to the cost of fitness incurred (Beceiro et al., 2013).

The activities of the fruit juices observed in the present study were in its consumable form, unlike many previous studies wherein activity of crude extracts had been tested. Overall, this study highlights the antibacterial efficacy of wild apple and gooseberry fruit juices.

\section{CONCLUSION}

The activity of the gooseberry and wild apple fruit juices against enteric, gastric, respiratory, urinary, and skin bacteria makes them highly potential to be proposed as a good natural product to supplement the treatment of such infections. Furthermore, the efficacy of juices against these bacteria makes it broad-spectrum anti-infective of a natural source without any inherent side effects, unlike chemotherapeutic agents.

Plausible treatment of infections of the drug-resistant bacteria by natural products such as wild apple and gooseberry fruit juices can be achieved, but extensive studies need to be done before implementing such therapies. Furthermore, the synergistic activity of commonly used drugs may be evaluated. Nevertheless, 
regular consumption shall always be beneficial with its other benefits and check the control of such infections making it a good natural resource of supplemental therapy.

\section{ACKNOWLEDGMENT}

The project was sponsored by Exotic Juices Limited, Manipur, India and supported by J.V. Gokal Charity Trust \& Shri Krishna Foundation, Mumbai. We are thankful to the Director, Haffkine Institute, Mumbai and also extend our thanks to the staff of Clinical Pathology department.

\section{REFERENCES}

Ahmad I, Beg AZ. Antimicrobial and phytochemical studies on 45 Indian medicinal plants against multi-drug resistant human pathogens. J Ethnopharmacol 2001;74:113-23.

Bag A, Bhattacharyya SK, Pal NK, Chattopadhyay RR. In vitro antimicrobial potential of Terminalia chebula fruit extracts against multidrug-resistant uropathogens. Asian Pac JTrop Biomed 2012;2:S1883-7.

Bansode D, Chavan M. Evaluation of antimicrobial activity and phytochemical analysis of papaya and pineapple fruit juices against selected enteric pathogens. Int J Pharm Bio Sci 2013;4:1176-84.

Beceiro A, Tomás M, Bou G. Antimicrobial resistance and virulence: A successful or deleterious association in the bacterial world? Clin Microbiol Rev 2013;26:185-230.

CLSI. Performance Standards for Antimicrobial Susceptibility Testing; Twenty-Fourth Informational Supplement. CLSI Document M100-S24. Wayne, PA: Clinical and Laboratory Standards Institute; 2014.

Cowan MM. Plant products as antimicrobial agents. Clin Microbiol Rev 1999;12:564-82.

Cushnie TT, Lamb AJ. Antimicrobial activity of flavonoids. Int J Antimicrob Agents 2005;26:343-56.

Dasaroju S, Gottumukkala KM. Current trends in the research of Emblica officinalis (Amla): A pharmacological perspective. Int J Pharm Sci Rev Res 2014;24:150-9.

Davidson PM. Chemical preservatives and natural antimicrobial compounds. In: Doyle MP, Beuchat LR, Montville TJ, editor. Food Microbiology: Fundamental and Frontiers. Washington, DC: ASM Press; 2001. p. 593-627.

Dharmananda S. Emblic Myrobalans: Amla; 2003. Available from: http: / /www.itmonline.org/arts/amla.htm. [Last accessed on 2016 Oct 06].

Facts O. Health Benefits of Indian Gooseberry or Amla; 2016. Available from: https://www.organicfacts.net/ health-benefits/fruit/indian-gooseberry-amla.html. [Last accessed on 2016 Dec 27].

Gonzalez LS $3^{\text {rd }}$, Spencer JP. Aminoglycosides: A practical review. Am Fam Physician 1998;58:1811-20.
Habib-ur-Rehman, Yasin KA, Choudhary MA, Khaliq N, Atta-ur-Rahman, Choudhary MI, et al. Studies on the chemical constituents of Phyllanthus emblica. Nat Prod Res 2007;21:775-81.

Hasan MR, Islam MN, Islam MR. Phytochemistry, pharmacological activities and traditional uses of Emblica officinalis: A review. Int Curr Pharm J 2016;5:14-21.

Hindi NK, Chabuck ZA. Antimicrobial activity of different aqueous lemon extracts. J Appl Pharm Sci 2013;3:74-8.

Jayana B, Prasai T, Singh A, Yami K. Study of antimicrobial activity of lime juice against Vibrio cholerae. Sci World J 2010;8:44-6.

Momand L, Zakaria R, Mikail M, JalalT, Ibrahim M, Wahab RA. Antimicrobial effect of Baccaurea angulata fruit extracts against human pathogenic microorganisms. Merit Res J Med Med Sci 2014;2:229-37.

Nagaland Post. Benefits of Wild Apple; 2012. Available from: http: / / www.nagalandpost.com/ channelnews/health/ HealthArticle.aspx?news=TkVXUzEwMDAyNjUzNQ\%3 D\%3D-Hugq5zPcqA\%3D. [Last accessed on 2016 Nov 29].

Negi PS. Plant extracts for the control of bacterial growth: Efficacy, stability and safety issues for food application. Int J Food Microbiol 2012;156:7-17.

Pandey A, Kaushik A, Tiwari SK. Evaluation of antimicrobial activity and phytochemical analysis of Citrus limon. J Pharm Biomed Sci 2011;13:1-7.

Robinson A, Fien S, Grassi MA. Nonhealing scalp wound infected with Aspergillus niger in an elderly patient. Cutis 2011;87:197-200.

Rojas JJ, Ochoa VJ, Ocampo SA, Muñoz JF. Screening for antimicrobial activity of ten medicinal plants used in Colombian folkloric medicine: A possible alternative in the treatment of non-nosocomial infections. BMC Complement Altern Med 2006;6:2.

Rudrappa U. Gooseberry Nutrition Facts; 2009. Available from: http: / /www.nutrition-and-you.com. [Last accesseed on 2016 Oct 04].

Rymbai H, Roy A, Deshmukh N, Jha A, Shimray W, War G, et al. Analysis study on potential underutilized edible fruit genetic resources of the foothills track of Eastern Himalayas, India. Genet Resour Crop Evol 2016;63:125-39.

Sawant L, Prabhakar B, Pandita N. Quantitative HPLC analysis of ascorbic acid and gallic acid in Phyllanthus emblica. J Anal Bioanal Tech 2012;1:1-4.

Shende K, Singh N, Negi P. Phytochemical characterization and biological activities of Docynia indica (Wall) fruit extracts. J Mol Genet Med 2016;10:1-5.

Shishoo C, Shah S, Rathod I, Patel S. Determination of vitamin C content of Phyllanthus emblica and chyavanprash. Indian J Pharm Sci 1997;59:268-70.

Shohaib T, Shafique M, Dhanya N, Divakar M. Importance of 
flavonoids in therapeutics. Hygeia JD Med 2011;3:1-18.

Spampinato C, Leonardi D. Candida infections, causes, targets, and resistance mechanisms: Traditional and alternative antifungal agents. Biomed Res Int 2013;2013:204237.

$\mathrm{Xu}$ HX, Lee SF. Activity of plant flavonoids against antibioticresistant bacteria. Phytother Res 2001;15:39-43.
Zlotek U, Mikulska S, Nagajek M, Swieca M. The effect of different solvents and number of extraction steps on the polyphenol content and antioxidant capacity of basil leaves (Ocimum basilicum L.) Extracts. Saudi J Biol Sci 2016;23:628-33. 